\title{
Orevisto
Observatório
}

ISSN n² 2447-4266

Vol. 4, n. 2, Abril-Junho. 2018

DOI: http://dx.doi.org/10.20873/uft.2447-4266.2018v4n2p298

\section{MODERNIDADE, CIÊNCIA, FILOSOFIA}

MODERNITY, SCIENCE, PHILOSOPHY

MODERNIDAD, CIENCIA, FILOSOFÍA

José Ternes ${ }^{1,2}$

\section{RESUMO}

O texto faz incursões por alguns textos de historiadores do pensamento ocidental objetivando apreender alguns aspectos decisivos da modernidade, como também mostrar que no tempo presente ocorre o desencantamento das promessas, demasiadamente otimistas, dos séculos XVII e XVIII. Do ponto de vista epistemológico, demonstra que a revolução da modernidade tem a ver com mudanças de objetos, argumentando que entender nossa época significa perguntar-se acerca da natureza dos novos objetos nascidos ou constituídos a partir dos começos do século XIX. Essa inversão epistemológica moderna requer outra relação com o saber, o que coloca para a Educação exigências

${ }^{1}$ Doutor em Filosofia pela Universidade de São Paulo (1993). Graduação em Letras Vernáculas pela Universidade Católica de Goiás, graduação em Filosofia - Fidene, mestrado em Filosofia pela Pontifícia Universidade Católica do Rio de Janeiro. Atualmente é professor titular da Universidade Católica de Goiás. É professor permanente do programa de Pós-Graduação em Educação (Mestrado e Doutorado) e professor colaborador no Mestrado de Letras da UCG. Email: joseternes@hotmail.com.

${ }_{2}^{2}$ Endereço de contato do autor (por correio): Pontifícia Universidade Católica de Goiás. Escola de Formação de Professores e Humanidades. Rua 227, Quadra 66, Quadra 14E, Número 119, $5^{\circ}$. Andar, Setor Leste Universitário, CEP 74605-080, Goiânia - Goiás, Brasil. 


\section{Crevisto}

ISSN n² 2447-4266

Vol. 4, n. 2, Abril-Junho. 2018

DOI: http://dx.doi.org/10.20873/uft.2447-4266.2018v4n2p298

maiores do que apenas a instrução. E questiona: se o saber moderno é tão frágil, tão efêmero, tão pouco seguro, por que com ele nos ocupar? Não poderia a escola, a universidade, estar a serviço de outras instâncias, mais urgentes talvez, do que o saber? O que se quer com a educação?

PALAVRAS-CHAVE: Filosofia; Modernidade; Educação.

\section{ABSTRACT}

The text makes inroads into some texts of historians of Western thought in order to apprehend some decisive aspects of modernity, but also to show that at the present time there is the disenchantment of the overly optimistic promises of the seventeenth and eighteenth centuries. From the epistemological point of view, it demonstrates that the revolution of modernity has to do with changes of objects, arguing that understanding our age means asking about the nature of new objects born or constituted from the beginnings of the nineteenth century. This modern epistemological inversion requires another relation with knowledge, which places more demands on education than instruction alone. And he asks: if modern knowledge is so fragile, so ephemeral, so uncertain, why should it occupy us? Could not the school, the university, be at the service of other instances, perhaps more urgent, than knowledge? What do you want with education?

KEYWORDS: Philosophy; Modernity; Education.

\section{RESUMEN}

El texto hace incursiones por algunos textos de historiadores del pensamiento occidental objetivando aprehender algunos aspectos decisivos de la modernidad, como también mostrar que en el tiempo presente ocurre el desencanto de las promesas, demasiado optimistas, de los siglos XVII y XVIII. Desde el punto de vista epistemológico, demuestra que la revolución de la modernidad tiene que ver con cambios de objetos, argumentando que entender nuestra época significa preguntarse acerca de la naturaleza de los 


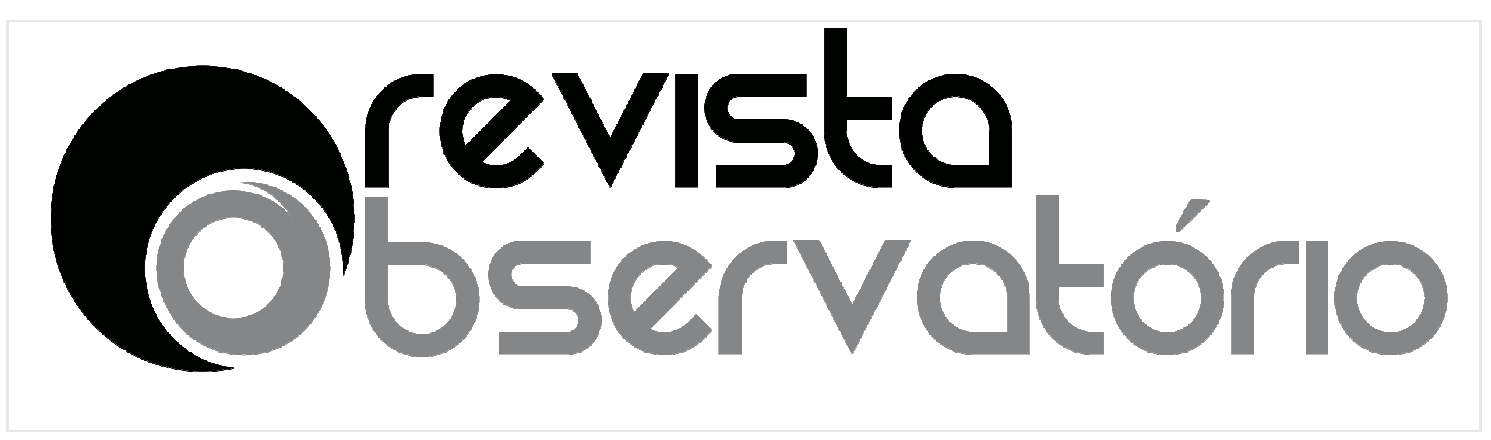

ISSN n² 2447-4266

Vol. 4, n. 2, Abril-Junho. 2018

DOI: http://dx.doi.org/10.20873/uft.2447-4266.2018v4n2p298

nuevos objetos nacidos o constituidos a partir de los comienzos del siglo XIX. Esta inversión epistemológica moderna requiere otra relación con el saber, lo que coloca para la Educación exigencias mayores que sólo la instrucción. Y pregunta: si el saber moderno es tan frágil, tan efímero, tan poco seguro, por qué con él nos ocupar? ¿No podría la escuela, la universidad, estar al servicio de otras instancias, más urgentes tal vez, que el saber? ¿Qué se quiere con la educación?

PALABRAS CLAVE: Filosofía; Modernidad; Educación.

Recebido em: 17.09.2017. Aceito em: 03.12.2017. Publicado em: 01.04.2018. 


\section{Orevisto
Observatório}

ISSN n² 2447-4266

Vol. 4, n. 2, Abril-Junho. 2018

DOI: http://dx.doi.org/10.20873/uft.2447-4266.2018v4n2p298

Quando se trata de Universidade, do ensino universitário, da pesquisa, pouco teria a dizer. Reduziria tudo a uma única afirmação: trata-se do lugar do pensamento. $\mathrm{O}$ da ciência, antes de tudo. Neste espaço, nem tudo é permitido. Valem, aqui, as palavras de Bachelard, de 1951, ao falar para um auditório de cientistas no Palais de la Découverte em Paris: "o visitante não deve entrar no Palácio da Descoberta para ver, deve vir aqui, e vir frequentemente, para compreender" (BACHELARD, 1972a, p. 137). Por isso, antes que para uma diversão de curiosos (badauds), dever-se-ia vir para um trabalho, o do espírito. É esse espaço de uma natureza singular que constitui o objeto de investigação deste breve artigo. E é ele que impõe, aos sujeitos que acolhe, uma ética também muito particular: é preciso adequar-se às exigências epistemológicas de seu tempo, de nosso tempo. É preciso ser moderno.

Vê-se logo que a questão não se reduz a terminologias. Aquém das discussões acerca do uso de palavras, há uma divisão mais radical: a que separa os intérpretes no que concerne à compreensão mesma de saber e de sua história. A divisão não está, pois, no reconhecimento dos fatos, mas no peso que se thes dá. A divisão se estabelece entre os que analisam movimentos de superficie, preservando o mesmo pensamento, e os que percebem, em determinados momentos da história, verdadeiras revoluções na ordem do saber. Para estes, o pensamento moderno seria muito mais do que um progresso, um avanço tecnológico, uma simples mudança de paradigma. Para estes, o pensamento pode, ou deve, mudar de natureza. "Com efeito, diz Bachelard, as crises de crescimento do pensamento implicam uma reforma total do sistema do saber. A cabeça bem-feita precisa então ser refeita. Ela muda de espécie. Opõe-se à espécie anterior por uma função decisiva. Pelas revoluções 


\section{Crevisto}

ISSN n² 2447-4266

Vol. 4, n. 2, Abril-Junho. 2018

DOI: http://dx.doi.org/10.20873/uft.2447-4266.2018v4n2p298

espirituais que a invenção científica exige, o homem torna-se uma espécie mutante, ou melhor dizendo, uma espécie que tem necessidade de mudar, que sofre por não mudar" (BACHELARD, 1972b). E François Jacob, em sua A lógica da vida, segundo Foucault (1970), "a mais notável história da biologia escrita até o momento", é constrangido a repetir essa tese em, pelo menos, duas ocasiões. Primeiro, quando descreve o nascimento da história natural no começo da idade clássica: "Com o século XVII, transforma-se a própria natureza do conhecimento" (JACOB, 1970, p. 37). Depois, na virada para a modernidade, quando se trata de mostrar a novidade essencial da biologia:

Para o século XIX, torna-se totalmente impróprio descrever o
funcionamento dos seres organizados em termos de gravidade, de
afinidade e de movimento. Para manter a coesão do ser, para
assegurar a ordem do vivo por oposição à desordem da matéria
inanimada, é preciso uma força de uma qualidade particular, o que
Kant chamava um princípio interior de ação, é preciso a vida. (JACOB,
1970, p. 104)

Não seria difícil de inventariar dezenas de testemunhas, a partir de contextos diferentes, narrando a mesma história: o pensamento não segue uma trajetória linear, como queriam os iluministas do século XVIII. O pensamento pode mudar, e muda efetivamente em sua essência. Na história do pensamento ocidental, podem-se, então, assinalar momentos de recomeço. E a modernidade é, sem dúvida, um desses acontecimentos, o mais importante, diria, pois diz respeito a nós mesmos. Estas palavras de Foucault se prestam para definir o que está em jogo:

Os últimos anos do século XVIII são rompidos por uma descontinuidade simétrica àquela que, no começo do século XVII, cindira o pensamento do Renascimento; então, as grandes figuras circulares onde se encerrava a similitude tinham-se deslocado e aberto para que o quadro das identidades pudesse desdobrar-se; e esse quadro agora vai por sua vez desfazer-se, alojando-se o saber num espaço novo (FOUCAULT, 1966, p. 229). 


\section{Crevisto}

ISSN n² 2447-4266

Vol. 4, n. 2, Abril-Junho. 2018

DOI: http://dx.doi.org/10.20873/uft.2447-4266.2018v4n2p298

Em poucas linhas, o filósofo esboça toda a história do pensamento ocidental do século XVI em diante. São três configurações, "quadros" (tableaux), que se sucedem, delimitando as três grandes epistemes analisadas em As palavras e as coisas. ${ }^{3}$ Não há continuidade entre tais disposições. São camadas, espaços epistemológicos, essencialmente diferentes entre si, e cuja origem, ou explicação, parece escapar às reais possibilidades da Arqueologia (nome dado às histórias dos saberes empreendidas por Foucault). O que se pode fazer, talvez, seja expor ou contrapor essas configurações, mostrar a novidade essencial que cada uma significa face à anterior. Cremos, no entanto, que nem isto seja aqui possível. Importa-nos explicitar o "espaço novo" em que o saber moderno se aloja, e qual o alcance desse acontecimento, as obrigações dele decorrentes. O que nos leva a dispensar as já tradicionais incursões pelo Renascimento. Da Idade Clássica assinalaremos apenas o indispensável, pois é esta época que aparece, quase sempre, como nosso anacronismo, aquilo que não mais "se presta ao saber"

A configuração epistemológica da Idade Clássica foi objeto de estudo de muitos historiadores das ciências ou dos saberes desde meados do século passado. Embora já mencionada, gostaria de retornar a La Logique du Vivant. Em poucas linhas, o epistemólogo historiador diz tudo:

\footnotetext{
Em menos de um século, os corpos vivos se limpam (...). Desembaraçam-se de sua camada de analogias, de similitudes e de signos, para aparecer na nudez das linhas e das superfícies determinadas pela visão. Não é mais possível colocar em um mesmo plano a forma de uma planta ou de um animal e as ideias que deles podem ter os viajantes, os historiadores ou os juristas. O que é lido ou ouvido não se iguala mais ao que é visto. O aspecto dos seres vivos,
}

\footnotetext{
3 Histoire de la folie e Naissance de la clinique oferecem-nos recortes semelhantes.

4 "Mais ce qu'il faut saisir et essayer de restituer, ce sont les modifications qui ont altéré le savoir lui-même, à ce niveau archaïque qui rend possibles les connaissances et le mode d'être de ce qui est à savoir" (FOUCAULT, M. 1966, p. 68).
} 


\section{Orevisto}

ISSN n² 2447-4266

Vol. 4, n. 2, Abril-Junho. 2018

DOI: http://dx.doi.org/10.20873/uft.2447-4266.2018v4n2p298

sua estrutura visível torna-se então objeto de análise e de classificação (JACOB, 1970, p.37).

Foucault fala em ordem visível. Toda episteme, esclarece o Prefácio a Les mots et les choses, configura, sempre, uma ordem. Mas, a ordem clássica, é singular: não somente constitui o ser dessa configuração epistemológica, mas se reduz à exterioridade observável das coisas. Antes da matematização, aquém do mecanicismo, antes, mesmo, do racionalismo, o que deve ser levado em conta seriam as exigências incontornáveis da Ordem. Aliás, a própria ideia de Natureza, conceito essencial dessa época, somente recebe sentido se relacionada com a de ordenação. A Natureza é natureza se ordenada, se investida de leis, de regularidades. Daí que conhecer nada mais é do que decifrar a Natureza, expor a sua infinita e imperturbável regularidade. Dar dela um quadro, o mais completo possível. G. Deleuze, ao falar da interpretação foucaultiana da Idade Clássica, assim se expressa:

O que define esse solo, o que constitui esta grande família de enunciados ditos clássicos, funcionalmente, é esta operação de desenvolvimento ao infinito, de formação de continuums, de desdobramentos de quadros: desdobrar, sempre desdobrar explicar. O que é Deus, senão a explicação universal, $\bar{o}$ desdobramento supremo? O desdobramento aparece aqui como um conceito fundamental, o primeiro aspecto de um pensamento operatório que se encarna na formação clássica (DELEUZE, 1988, p. 1345).

Correndo o risco de ser prolixo, insistiria nesse pensamento operatório, desdobramento ao infinito, no próprio discurso clássico. Ao tratar do estatuto epistemológico do Gabinete de História Natural, Diderot escreve o seguinte:

Para formar um cabinet d'Histoire naturelle, diz Diderot, não é suficiente reunir sem escolher, e amontoar sem ordem e sem gosto, todos os objetos da História natural que a gente encontra; é necessário saber distinguir o que merece ser guardado do que é necessário rejeitar e dar a cada coisa uma disposição conveniente. A ordem de um cabinet não pode ser aquela da natureza; a natureza apresenta sempre uma sublime desordem (DIDEROT, 2001, p. 254). 


\title{
Crevisto
}

ISSN n² 2447-4266

Vol. 4, n. 2, Abril-Junho. 2018

DOI: http://dx.doi.org/10.20873/uft.2447-4266.2018v4n2p298

Essa ordem não poderia, então, estar a cargo de qualquer indivíduo. Era ofício de uma figura emblemática da Idade Clássica, o naturalista. O Gabinete, efetivamente, é a ciência realizada. Deveria, continua Diderot, gravar "na memória a imagem da natureza" (DIDEROT, 2001, p. 257). Sua organização é feita, diz o naturalista d'Aubenton, segundo

\begin{abstract}
A ordem metódica que distribui as coisas que ele compreende em classes, em gêneros e em espécies; assim os animais, os vegetais, e os minerais serão exatamente separados uns dos outros; cada reino terá uma repartição à parte. A mesma ordem subsistirá entre os gêneros e as espécies; colocam-se os indivíduos de uma mesma espécie uns perto dos outros, sem que jamais seja permitido distanciá-los. Ver-seão as espécies em seus gêneros, e os gêneros em suas classes. Tal é a arrumação que recomendam os princípios imaginados para facilitar o estudo da História natural; tal é a única ordem que pode realizá-los (D'AUBENTON, in DIDEROT, 2001, p. 254).
\end{abstract}

Percebe-se que tal empreendimento responde às exigências clássicas da visibilidade. A ordem do cabinet é dada ao olhar: "neste gênero de estudo, quanto mais se vê, mais se sabe", diz D'Aubenton (in DIDEROT, p. 259).

Gostaria de insistir no mais fundamental. O cabinet d'Histoire naturelle tem um sentido preciso na disposição geral do saber clássico, principalmente no século XVIII. Ao lado dos jardins botânicos, ${ }^{5}$ configura o que há de mais adequado a um tipo de conhecimento que é, por excelência, visão. Ambos esses lugares têm por finalidade dar a conhecer a estrutura visível. Traduzem uma ordem epistemológica que marcou o pensamento ocidental durante dois séculos. Saber fora, de Descartes a D'Alembert, antes de tudo, representação.

Ora, tal disposição epistemológica encontra sua exaustão na virada para o século XIX. Estamos na época das revoluções científicas modernas, mas, principalmente, de mudanças no modo de ser de toda a cultura ocidental:

\footnotetext{
${ }^{5}$ A Zoologia teve fortuna menor nessa época, talvez, como lembra Jacob, porque os animais fossem menos dóceis ao olhar geométrico dominante.
} 


\section{Oevisto}

ISSN n² 2447-4266

Vol. 4, n. 2, Abril-Junho. 2018

DOI: http://dx.doi.org/10.20873/uft.2447-4266.2018v4n2p298

mutações que fazem com que de súbito as coisas não sejam mais percebidas, descritas, enunciadas, caracterizadas, classificadas e sabidas do mesmo modo e que, no interstício das palavras ou sob sua aparência, não sejam mais as riquezas, os seres vivos, o discurso que se oferecem ao saber, mas seres radicalmente diferentes (FOUCAULT, 1966, p. 229).

O conhecimento-visão, dado na relação de exterioridade entre sujeito e objeto $^{6}$, perde força, agora. Não é mais na ordem das razões, como queria Descartes, que a verdade deve ser procurada. Seu espaço adequado deixa de ser a representação. Esgota-se, como se expressa G. Canguilhem, o Cogito (CANGUILHEM, 2012). E um novo signo, substituindo o autor das Regulae, aparece, como limiar da modernidade: Kant. Não nos parece, pois, acaso o fato de a Crítica da Razão Pura começar com uma referência à experiência e ao tempo. Foucault vê, nessa inversão copernicana do pensamento ocidental, a constituição de um novo solo epistemológico. E lhe dá um nome: História. Assim como a Ordem, na Idade Clássica, não era apenas um capricho de uma razão meticulosa, mas o lugar, o único lugar em que os seres poderiam se dar a conhecer, assim também, na virada para o século XIX, a história é mais do que uma entre tantas possibilidades analíticas. Ela se torna o único espaço a partir do qual nossas verdades poderão vir à existência. Tomemos esta, um pouco longa, citação. Ela permite ver, com muita argúcia, a revolução que pretendemos mostrar:

Mas vê-se bem que a História não deve ser aqui entendida como a coleta das sucessões de fatos, tais como se constituíram; ela é o modo de ser fundamental das empiricidades, aquilo a partir de que elas são afirmadas, postas e repartidas no espaço do saber para eventuais conhecimentos e para ciências possíveis. Assim como a Ordem no pensamento clássico não era a harmonia visível das coisas, seu ajustamento, sua regularidade ou sua simetria constatados, mas o

\footnotetext{
6 "No conhecimento, há apenas dois pontos a considerar, a saber: Nós que conhecemos e os objetos a conhecer" ( DESCARTES, R. Regras para a direção do espírito. XII. Lisboa: Estampa, 1977, p. 66).
} 


\section{Oevisto}

ISSN n² 2447-4266

Vol. 4, n. 2, Abril-Junho. 2018

DOI: http://dx.doi.org/10.20873/uft.2447-4266.2018v4n2p298

espaço próprio de seu ser e aquilo que, antes de todo conhecimento efetivo, as estabelecia no saber, assim também a História, a partir do século XIX, define o lugar de nascimento do que é empírico, lugar onde, aquém de toda cronologia estabelecida, ele assume o ser que lhe é próprio. É por isso certamente que tão cedo a História se dividiu, segundo um equívoco que sem dúvida não é possível vencer, entre uma ciência empírica dos acontecimentos e esse modo de ser radical que prescreve seu destino a todos os seres empíricos e a estes seres singulares que somos nós. A História, como se sabe, é efetivamente a região mais erudita, mais informada, mais desperta, mais atravancada talvez de nossa memória; mas é igualmente a base a partir da qual todos os seres ganham existência e chegam à sua cintilação precária. Modo de ser de tudo o que nos é dado na experiência, a História tornou-se assim o incontornável de nosso pensamento (FOUCAULT, 1966, p. 231).

Ocupemo-nos, brevemente, com essa disposição geral do saber ocidental moderno definido por Foucault como histórico. Estamos acostumados a distinguir, desde Marx, entre natureza e cultura. Somente esta, obra do homem, ocuparia um lugar na história. Esqueçamos esta demarcação. Para o arqueólogo, a partir do século XIX, todos os seres nascem e morrem. Os seres clássicos herborizavam. Os modernos, historicizam. Vejamos o que isto significa. Interroguemos alguns desses novos objetos históricos, antes impensáveis.

Naissance de la clinique lembra duas perguntas de médico que servem de baliza para dois regimes de verdade. $\mathrm{O}$ diálogo entre o médico e o doente até o fim do século XVIII costumava começar com esta pergunta: Qu'avez vous? - Já o médico moderno começa com uma pergunta bem diferente: Où avez vous mal (FOUCAULT, 1972, p. XIV). Perguntas banais, aparentemente e que, ainda hoje, parecem transitar, sem problema, no interior de nossa linguagem comum. O olhar mais atento do arqueólogo, no entanto, vê mudanças muito sérias: "Esta ordem do corpo sólido e visível é, entretanto, apenas uma das maneiras da medicina espacializar a doença. Nem a primeira, sem dúvida, nem a mais fundamental. Houve e haverá outras distribuições do mal" (FOUCAULT, 1972, p. XIV). 


\section{Oeveristo}

ISSN n² 2447-4266

Vol. 4, n. 2, Abril-Junho. 2018

DOI: http://dx.doi.org/10.20873/uft.2447-4266.2018v4n2p298

Para a idade clássica o mal ocupava, efetivamente, outro espaço. Não coincidia com o corpo doente. "A coincidência exata do corpo da doença com o corpo do homem doente é um dado histórico e transitório. Seu encontro só é evidente para nós..." (FOUCAULT, 1972, p. XIX). A doença clássica era uma espécie natural, dada no quadro sem profundidade da representação. Quando os modernos não mais entendem a doença como espécie, quando a desentificam e lhe dão um caráter apenas adjetivo, quando a percebem como lesão do tecido, e não como hóspede do corpo, opera-se uma das mais significativas revoluções epistemológicas da medicina. É o corpo o lugar da verdade, agora. E este é, de pleno direito, histórico. A verdade da doença será, então, a verdade do corpo doente, um acontecimento da vida do homem. Um acontecimento sempre relacionado com o nascimento e a morte. No caso particular da medicina patológica, mais ostensivamente com a morte: "A noite viva se dissipa na claridade da morte" (FOUCAULT, 1972, p. 149).

A arqueologia dos objetos empíricos de Les mots et les choses oferecenos conclusões bastante próximas das de Naissance de la clinique. O filósofo investiga o nascimento da vida, do trabalho e da linguagem na passagem para o século XIX. Objetos, cuja existência seria possível somente com profundas modificações no modo de ser do pensamento ocidental. Fora preciso, lemos no começo do Capítulo VIII do livro, que o saber mudasse "de natureza e de forma" (FOUCAULT, 1966, p. 264). Fora preciso buscar em outro espaço, que não o da representação, as condições de possibilidade desses objetos. Tal espaço, acabamos de ver, é a História. Três pequenos trechos nos parecem suficientes para mostrar o que acontecera:

O valor deixou de ser signo, tornou-se um produto. (...) desde Ricardo, a possibilidade da troca está assentada no trabalho; e a teoria da produção, doravante, deverá sempre preceder a da circulação (FOUCAULT, 1966, p. 2667). 


\title{
Crevisto
}

ISSN n² 2447-4266

Vol. 4, n. 2, Abril-Junho. 2018

DOI: http://dx.doi.org/10.20873/uft.2447-4266.2018v4n2p298

\begin{abstract}
O ser vivo era uma possibilidade da classificação natural; o fato de ser classificável é agora uma propriedade do ser vivo. (...) A vida não é mais o que se pode distinguir, de maneira mais ou menos certa, do mecânico; é aquilo em que se fundam todas as distinções possíveis entre os seres vivos (FOUCAULT, 1966, p. 280-1).

O conhecimento clássico era profundamente nominalista. A partir do século XIX, a linguagem se dobra sobre si mesma, adquire sua espessura própria, desenvolve uma história, leis e uma objetividade que só a ela pertencem. Tornou-se um objeto de conhecimento entre tantos outros (FOUCAULT, 1966, p. 309).
\end{abstract}

Os três trechos, é fácil perceber, referem-se a três saberes, emergentes no começo do século XIX: a economia política, a biologia e a filologia (ou história das línguas). Seus objetos (trabalho, vida, linguagem) significaram mudanças epistemológicas fundamentais na história do pensamento ocidental. Eles são, constitutivamente, históricos. Todo valor somente se esclarece referido às suas condições de produção, ao trabalho do homem. Tem sempre uma origem, um lugar de nascimento, mas, ao mesmo tempo, está sempre sob a ameaça da desvalorização, do desaparecimento. Nascimento e morte são, também, condições para o conhecimento dos vivos. Finalmente, a linguagem torna-se objeto separado, assume, como vimos, densidade própria. Torna-se acontecimento único, cuja história pode ser explicada. As línguas, também elas, nascem e morrem.

Foucault, no entanto, não é o único a assinalar o modo próprio de ser do pensamento moderno. Entre muitos, Bachelard talvez seja um dos mais representativos e, sem dúvida, dos mais originais. Formado em Física, seu interesse, como epistemólogo, foram as revoluções dos saberes que, um pouco genericamente, podem ser chamados matemáticos. as novas geometrias, a química, as diversas físicas modernas. Algumas linhas de Le nouvel esprit 


\section{Orevisto}

ISSN n² 2447-4266

Vol. 4, n. 2, Abril-Junho. 2018

DOI: http://dx.doi.org/10.20873/uft.2447-4266.2018v4n2p298

scientifique nos parecem suficientes para mostrar a novidade essencial das ciências modernas assinalada pelo filósofo:

Na ciência dos últimos séculos, a unidade da noção de massa, seu caráter imediato e evidente, provinham da vaga intuição de quantidade de matéria. Tinha-se uma tal confiança na tomada concreta do espírito sobre a Natureza que as definições newtonianas pareciam a simples precisão de uma ideia vaga mas fundamentada (...). Assim, a noção primeira de massa, bem fundada ao mesmo tempo numa teoria e numa experiência, parecia dever escapar a toda análise. Esta ideia simples parecia corresponder a uma natureza simples. Sobre este ponto a ciência parecia uma tradução imediata da realidade.

Ora, as fórmulas de dimensões, que fixam as relações das unidades entre si, não decidem tão soberanamente como se acreditou, às vezes, da natureza das entidades que elas caracterizam. Por outro lado, a reivindicação de uma tomada imediata sobre o concreto é frequentemente bastante temerária. A Relatividade, neste ponto particular, vai ser ao mesmo tempo menos realista e mais rica que a ciência antecedente. Ela vai desdobrar uma noção simples, dar uma estrutura matemática a uma noção concreta. Com efeito, a Relatividade fornece a prova de que a massa de um móvel é função de sua velocidade (BACHELARD, 1978, p. 50-1).

Poderíamos fazer o inventário de centenas de passagens na obra bachelardiana que mostram que a ciência moderna se constitui contra a ciência clássica, contra Galileu, Newton, Euclides, mas principalmente contra uma certa filosofia das ciências, a filosofia cartesiana, cujo ponto de partida são as ideias simples. Para Bachelard, as revoluções científicas modernas exigem revoluções epistemológicas correspondentes. E nem sempre o progresso científico vem acompanhado de progressos filosóficos. Nem sempre a ciência tem a filosofia que merece. Nova ciência, novo espírito científico.

É impossível, aqui, ocuparmo-nos com algum rigor com a epistemologia bachelardiana. Nossa intenção foi apenas mostrar que Foucault não está sozinho. Suas análises são, mesmo, bastante circunstanciais. Seu método, como todo método, bastante redutivo. Bachelard investiga outros objetos, particularmente os quantitativos, e com outros instrumentos, aqueles da 


\section{Qrevisto}

ISSN n² 2447-4266

Vol. 4, n. 2, Abril-Junho. 2018

DOI: http://dx.doi.org/10.20873/uft.2447-4266.2018v4n2p298

epistemologia histórica. Poderíamos acrescentar outros historiadores do pensamento ocidental, igualmente notáveis: Prigogine, Geymonat, Cavaillés, Koyré, Maturana etc. Todos eles, apesar das diferenças, deixam muito claro que nossa modernidade tem uma natureza própria, e não pode ser entendida como o simples aperfeiçoamento de uma história de há muito já preparada. E mais, tal natureza diz respeito ao pensamento. As mudanças são, em essência, de ordem conceitual.

As incursões por alguns textos de historiadores do pensamento ocidental, acreditamos, permitem perceber alguns aspectos decisivos da modernidade. Permitem também, como bem mostram Ilya Prigogine e Isabelle Stengers, tomar consciência de que nosso tempo nasce do desencantamento das promessas, demasiadamente otimistas, dos séculos XVII e XVIII. Do ponto de vista estritamente epistemológico, podemos dizer, sem dúvida que a revolução da modernidade tem a ver com mudanças de objetos. Entender nossa época significa perguntar-se acerca da natureza dos novos objetos nascidos ou constituídos a partir dos começos do século XIX.

Vimos, com Foucault, que os novos objetos empíricos são históricos. Pensamos que Bachelard, e muitos outros, mostram o mesmo em outros campos do saber. A nosso ver, a historicização dos objetos, seu deslocamento para fora do espaço da representação, constitui o acontecimento mais sério dos últimos séculos da cultura ocidental, tão importante, sem dúvida, quanto o nascimento do Logos (ou da Theoria) na Antiga Grécia ou a revolução galileana no começo do século XVII. Na verdade, o pensamento moderno transgride a própria noção de ciência, ou de verdade científica, que o Ocidente adotara desde Platão. Universalidade, objetividade, pontos de partida absolutamente seguros etc., perdem, agora, muito de seu sentido. A ciência clássica se 


\section{Crevisto}

ISSN n² 2447-4266

Vol. 4, n. 2, Abril-Junho. 2018

DOI: http://dx.doi.org/10.20873/uft.2447-4266.2018v4n2p298

constituíra segundo o ideal laplaceano de um determinismo universal. $O$ demônio de Laplace, muito mais do que uma possibilidade real, traduz uma possibilidade de princípio, diz Prigogine (1984, p. 59), a de "observar, num momento determinado, a posição e a velocidade de cada massa constitutiva do Universo, e daí deduzir a evolução universal, tanto na direção do passado como na do futuro". Ideal somente possível numa relação de exterioridade entre Sujeito e Objeto. Ao se historicizarem, os novos objetos perturbam aquela relação. Sujeito e objeto deixam de ser pura exterioridade. Assumem uma densidade própria. Intensificam-se. Recebem interioridade e profundidade. $\mathrm{O}$ objeto clássico, dado na representação, não podia ser profundo. As imagens, com efeito, não têm interior. Oferecem-nos quadros, ordens dadas ao olhar. Não há como, e não era preciso, ir além da ocularidade: ver, saber. Observamolo nos procedimentos dos naturalistas, dos gramáticos, dos economistas clássicos. Galileu, segundo Koyré (1982, p. 53), nos presentearam com um mundo "sem nenhuma alegria". Os habitantes desse mundo são da ordem da geometria, e esta, a de Euclides, é plana, seus objetos se dão na superfície. Quando Bichat diz a seus alunos: "abram alguns cadáveres" que dar uma instrução de rotina. Essa frase está na base de uma reorganização mais geral do saber. O médico é contemporâneo de Cuvier, de Ricardo, de Nietzsche, de Poincaré, de Kant, de Darwin, de Hölderlin. Agora, não se trata mais de dar o quadro (plano) em que os seres podem ser localizados, ou vistos. Agora é preciso que os seres falem. Como na Renascença, assistimos, a partir do século XIX o retorno da prosa do mundo, ou segundo Foucault, o retorno da linguagem.

\footnotetext{
${ }^{7}$ Frase de Xavier Bichat que Foucault usou como título do capítulo VIII de La naissance de la Clinique.
} 


\section{Oevisto}

ISSN n² 2447-4266

Vol. 4, n. 2, Abril-Junho. 2018

DOI: http://dx.doi.org/10.20873/uft.2447-4266.2018v4n2p298

Se, no entanto, o saber moderno recobra a alegria perdida, não há motivos para muita festa. Na verdade, o que nos é devolvido, é a finitude. Conhecer, hoje, é ter que se haver com o finito, o condicionado, a história. É ter que se confrontar, constantemente, com a possibilidade de superação, de envelhecimento, de degeneração, mesmo, do objeto. Mais do que isso, em certos setores da ciência moderna, o objeto é tão precário que somente nos é dado ao saber no movimento mesmo do conhecer: "Pode-se dizer que, durante vinte e cinco anos, Lobatchewsky ocupou-se mais em estender sua geometria do que em fundá-la. Igualmente, não se podia fundá-la a não ser estendendo-a. Parece que Lobatchewsky deseja provar o movimento, avançando" (BACHELARD, 1978, P. 29). A mesma lição se aprende com a microfísica: "O fóton é evidentemente um tipo de coisa-movimento" (BACHELARD, 1978, p. 66).

E aqui se coloca uma das coisas mais importantes da discussão, ou, se quisermos, uma tremenda contradição também: reivindicamos a inserção de todo saber na existência concreta dos homens. Ao mesmo tempo, clamamos pelo universal, por fundamentos que nos deem, novamente, segurança. Os epistemólogos, sua maioria, reconhecem que, infelizmente, não há mais fundamentos. Que o saber não está inscrito, a priori, na Natureza, ou em outro ponto fixo, bastando alguma competência para a ele aceder. Ele é nossa invenção, depende de nosso ponto de vista: "tudo é dito por um observador" (MATURANA, 1997, p. 53). A modernidade elide a tradicional separação entre sujeito e objeto. Se ainda podemos utilizar hoje tais termos, precisamos sempre estar atentos ao fato de que tanto um quanto outro são relativos, se constituem mutuamente. Bachelard arrisca, inclusive, um novo termo: projeto. Mas a palavra não é o mais importante. Importa assinalar que a moderna configuração do saber coloca algumas lições, ou, talvez, algumas exigências para aqueles que 


\section{Oevisto}

ISSN n² 2447-4266

Vol. 4, n. 2, Abril-Junho. 2018

DOI: http://dx.doi.org/10.20873/uft.2447-4266.2018v4n2p298

com ele se ocupam. E isto vale, em primeiro lugar, para os educadores. Não nos compete, seria muita arrogância, colocar qualquer base para uma pedagogia (um saber da educação), e, muito menos, para algo que se denomina ciências humanas. Pensamos, porém, que as atuais pedagogias (o plural deve ser levado a sério) deveriam estar atentas para a natureza essencialmente nova da ciência moderna e do próprio pensamento moderno.

Há, sem dúvida, projetos pedagógicos que nascem como reação ao pensamento moderno. Anacronismos são perfeitamente normais na história. Trata-se, quase sempre, no entanto, de rituais à margem do exercício efetivo do pensamento. Pretende-se, muitas vezes, que as reações sejam de ordem política e moral, antes que epistemológicas. Seria possível um novo espírito científico acoplado a velhos moralismos, a fundamentalismos pré-colombianos? Numa cultura de simples justaposição, tudo é possível. Mas é justamente isto que o pensamento moderno nega: que as coisas se deem numa ordenação artificial, numa acomodação de superfície. Quando um Bachelard propõe um polifilosofismo, prega, sem dúvida a diferença, não porém, de opiniões, mas de pensamentos, de filosofias principalmente. Quando Foucault assinala a estreita relação entre poder e saber, não defende qualquer totalitarismo. Ao contrário, mostra que, se há algo de que não podemos abrir mão, trata-se, antes de tudo, do pensamento. E este é sempre provisório.

Retornemos, porém, a nosso tema, o da educação. Ou, talvez, o da relação desta com o que acabamos de expor. Gostaríamos de convidá-los a um passeio, a uma leitura sem compromissos. Os educadores poderiam (ou deveriam) fazer muitos outros passeios. poesia, romances, música, teatro, pintura, museus, encontros científicos, cinema... Estamos bastante ocupados para essas coisas. No entanto, se não são imediatamente úteis, podem ter 


\section{Oevisto}

ISSN n² 2447-4266

Vol. 4, n. 2, Abril-Junho. 2018

DOI: http://dx.doi.org/10.20873/uft.2447-4266.2018v4n2p298

alguma repercussão. Sua utilidade é abrir o espírito, arejá-lo. Ler Bachelard, Koyré, Canguilhem, Maturana, Foucault (especialmente o arqueólogo, mais difícil), Prigogine, e muitos outros, pode parecer perda de tempo. O que, no entanto, investigam estes filósofos? Ocupam-se com a natureza do pensamento, o moderno em especial. E o que fazem os educadores: ocupam-se, incansavelmente, com o ensino. Mas ensino de que? De matemática, física, língua pátria, história, teologia, sociologia, psicologia, filosofia, etc. Ensino do pensamento moderno, em última instância. Não estamos, pois, tão distantes! Antes que buscar lições de fora (e as encontramos, de todos os matizes), talvez o próprio pensamento moderno coloque aos educadores algumas exigências. Uma coisa é certa: não podemos mais ser clássicos, no sentido há pouco assinalado.

A inversão epistemológica moderna, acreditamos, requer outra relação com o saber. Não é mais possível, ou desejável ser apenas cartesiano. Uma relação de exterioridade seria, hoje, o empobrecimento do saber. Este não é mais, como queria Diderot, simples objeto de instrução. Instruir pode bem ser tarefa primeira dos povos civilizados. ${ }^{8}$ O Relatório Delors o mostrara bem. Mas, instruir é muito pouco.

A educação, hoje, certamente se coloca exigências maiores do que a instrução. E tais exigências nascem, a nosso ver, do modo de ser, da natureza mesma do saber moderno. Saber-invenção, antes que saber-espetáculo. É compreensível, e perfeitamente aceitável, que D'Aubenton atribua ao Cabinet d'Histoire Naturelle du Roy a função precípua da ocularidade. Era preciso que o visitante tivesse uma visão clara e distinta da ordem dos seres da Natureza.

\footnotetext{
${ }^{8}$ Não nos parece ocasional o fato de Diderot iniciar seu Plano de um Universidade ou de uma Educação Pública em todas as Ciências falando da instrução. "Instruir uma nação é civilizá-la" (DIDEROT, D. Obras I. São Paulo: Perspectiva, 2000, p. 263).
} 


\section{Oevisto}

ISSN n² 2447-4266

Vol. 4, n. 2, Abril-Junho. 2018

DOI: http://dx.doi.org/10.20873/uft.2447-4266.2018v4n2p298

Saber era, antes de tudo, para o século XVIII, VER. E instruir era possibilitar ver melhor. Ora, um biólogo, ou um professor de biologia, que, em nossos dias, reduzisse seu saber ao visível, que se desse por satisfeito com um conhecimento dado ao olhar, que se contentasse em dar visibilidade a seus objetos, seria uma figura, no mínimo, anacrônica. Nossa modernidade nasce quando o princípio da visibilidade perde força, quando o visível e o invisível se reaproximam. Quando, enfim, o invisível assume privilégios epistemológicos iguais aos da visão. Um físico contemporâneo que limitasse suas aulas a dar aos alunos instruções sobre o que é visível seria bastante estranho. Os objetos da física moderna, da microfísica, por exemplo, não se dispõem ao olhar. Mais do que coisas observáveis e mensuráveis, são pensamentos, "sombras de um número". 9 Mais do que coisas a ver, são seres a pensar.

Se o educador tem algo a aprender investigando o pensamento moderno, talvez seja essa inversão no modo de saber. Na modernidade, ordem e desordem, visível e invisível, luz e penumbra, pensado e impensado, pertencem a um mesmo movimento. $E$ isto não tem nada com irracionalidade ou com ceticismo. Ao contrário, é do lado da razão, da formação intelectual, que está a possibilidade de sucesso. O homem moderno, mais do que adquirir conhecimentos, precisa, constantemente, recriá-los. Um projeto de Enciclopédia, ou, como vemos em Condorcet, um Esboço dos Progressos do Espírito Humano, perderiam, hoje, o interesse que experimentavam no século XVIII. Pelo menos, não podem mais ser a primeira tarefa do pesquisador, do educador. A modernidade nos obriga, sem dúvida, a rever a própria ideia de saber, de ciência, particularmente, bem como a de mestre. E não nos parece

\footnotetext{
9 "Exprimons donc cette double suprématie du nombre sur la chose et du probable sur le nombre par une formule polémique: la substance chimique n'est que l'ombre d'un nombre"(BACHELARD, G. Le nouvel esprit scientifique, p. 86.
} 


\section{Crevisto}

ISSN n² 2447-4266

Vol. 4, n. 2, Abril-Junho. 2018

DOI: http://dx.doi.org/10.20873/uft.2447-4266.2018v4n2p298

ocasional a proliferação, ao infinito, de discussões acerca dessa figura inquestionável há poucos anos.

De uma coisa temos certeza: não é mais possível imaginar fundamentos na atualidade, pois, simplesmente, todos os fundamentos entraram em ruína há, pelo menos, dois séculos. Encontramo-nos, no momento, enredados em mil polêmicas ${ }^{10}$, envolvendo temas como modernidade, pós-modernidade, estruturalismo, pós-estruturalismo, culturalismo, conhecimento em rede, etc. Movimentos de superfície, diria Foucault. Provavelmente tudo isso compõe um solo comum, inscreve-se numa configuração mais ampla do saber de nosso tempo, e que se caracteriza, justamente, pela dispersão. Em todo caso, a configuração epistemológica contemporânea não nos parece autorizar bases muito seguras. Os debates atuais se desenvolvem, certamente, a partir de referenciais outros que os estritamente epistemológicos. E não cabe, aqui, a pergunta acerca de sua legitimidade. Pensamos, no entanto que há questões que emergem do interior do próprio pensamento atual, e que têm seu peso. Os epistemólogos insistem, mesmo, que o que deve ser levado em conta, antes de tudo, é o saber, que nossa relação é com o saber, antes de tudo, e que tudo o mais deveria ser pensado em função deste. Mas, se o saber moderno é tão frágil, tão efêmero, tão pouco seguro, por que com ele nos ocupar? Não poderia a escola, a universidade, estar a serviço de outras instâncias, mais urgentes talvez, do que o saber? O que se quer com a educação? Aprender a conhecer, dizem uns. Logo, porém, nos damos conta que o conhecimento é um processo que se faz contra conhecimentos anteriores. Mesmo nessa esfera tão pouco normativa que é a poesia, Bachelard nos convida a "nos

\footnotetext{
${ }^{10}$ Veja-se, por exemplo, o vol 2 da série "Cultura, Memória e Currículo", organizado por Alice C. Lopes e Elizabeth Macedo, sob o título: Currículo: debates contemporâneos. São Paulo: Cortez, 2002.
} 


\section{Gevisto
Observatório}

ISSN n² 2447-4266

Vol. 4, n. 2, Abril-Junho. 2018

DOI: http://dx.doi.org/10.20873/uft.2447-4266.2018v4n2p298

desfilosofarmos". E Foucault, já no auge (e no fim) de sua produção, pergunta: "De que valeria a obstinação do saber se ele assegurasse apenas a aquisição dos conhecimentos e não, de certa maneira, o descaminho daquele que conhece?" (FOUCAULT, 1984, p.13). Aprender a fazer, dizem outros (ou os mesmos?). A modernidade toda, mas também a idade clássica, e muitos outros, desde os antigos, privilegiam o fazer. Em nosso tempo, lembra Hannah Arendt, não se corre o risco de reduzir o fazer ao trabalho, quando o que conta é a ação? E as competências que visam apenas o mercado de trabalho? Aprender a fazer nada não seria tão fundamental quanto, simplesmente, aprender a fazer? Dizem também que a grande tarefa seria aprender a viver juntos. Maturana nos ensina que tal fórmula é bastante velha. É, na verdade, biológica, quer dizer, tem a idade da vida. A ciência moderna é uma escola do viver juntos. Bachelard mostra, exaustivamente o caráter inetersubjetivo da ciência em nossos dias. Usa, mesmo, a imagem cidade científica. Paradoxalmente, nessa cidade, a tolerância é zero. Viver juntos, aqui, impõe um engajamento racionalista. No entanto, e isto é mais um paradoxo, a vida intelectual supõe a solidão. Ao contrário do que se possa imaginar, a solidão é condição para o trabalho coletivo. Não a solidão vazia, mas a do trabalho: "...a vela, companheira de solidão, é principalmente companheira de trabalho solitário. A vela não ilumina um cubículo vazio, ilumina um livro" (BACHELARD, 1961, p. 54). E há o sonho de uma pedagogia do Ser. Ora, a novidade do pensamento moderno parece estar justamente nisto: a reabilitação do Não-Ser. Sartre diria do Nada (ressalte-se o sentido preciso de tal conceito). Mas é toda a configuração epistemológica moderna, desde o nascimento das ciências empíricas, com seus objetos "quase transcendentais", que são a vida, a linguagem e o trabalho, até as ciências matemáticas, com seus seres (ou não-seres) eminentemente abstratos, bem 


\title{
Crevisto
}

ISSN n² 2447-4266

Vol. 4, n. 2, Abril-Junho. 2018

DOI: http://dx.doi.org/10.20873/uft.2447-4266.2018v4n2p298

como um modo muito particular de se fazer filosofia, mas também de se fazer arte (música, literatura, pintura), e desses saberes epistemologicamente bastante incômodos, as ciências humanas, toda essa configuração do saber recusa pontos de referência seguros, recusa, digamos, o Ser. Todos esses saberes se desdobram em estreita relação com a morte. Suas verdades são estabelecidas, com mais frequência, pelas vias do não-ser, inscrevem-se na esfera do possível, não do que é. Seria ainda possível, neste começo do século XXI, dizer, com alguma segurança, eu sou? Foucault, de maneira magistral, descreve a situação ambígua em que nos encontramos:

\begin{abstract}
(...) posso eu dizer, com efeito, que sou essa linguagem que falo e na qual meu pensamento desliza ao ponto de nela encontrar o sistema de todas as suas possibilidades próprias, mas que, no entanto, só existe sob o peso de sedimentações que ele jamais será capaz de atualizar inteiramente? Posso eu dizer que sou este trabalho que faço com minhas mãos, mas que me escapa, não somente quando o concluo, mas antes mesmo de o haver encetado? Posso eu dizer que sou essa vida que sinto no fundo de mim, mas que me envolve tanto pelo tempo formidável que ela impulsiona consigo e que me eleva por um instante sobre sua crista, quanto pelo tempo iminente que me prescreve minha morte? Posso dizer tanto que sou quanto que não sou tudo isso; o cogito não conduz a uma afirmação do ser, mas abre justamente para toda uma série de interrogações onde o ser está em questão (FOUCAULT, 1966, p. 335-6).
\end{abstract}

Acreditamos que esta passagem do livro de Foucault, com sua dose de ironia, nos oferece o tom de tudo o que dissemos. O tempo seguro do Cogito parece ter encontrado seu esgotamento. Bases firmes, pilares, abóbadas, torres, palácios são sempre possíveis, mas como reabilitação de uma metafísica elidida há bastante tempo.

\section{Referências}

BACHELARD, G. "L'actualité de l'histoire des sciences", in L'engagement rationaliste. Paris: PUF, 1972a. 


\section{Qbevisto}

ISSN n² 2447-4266

Vol. 4, n. 2, Abril-Junho. 2018

DOI: http://dx.doi.org/10.20873/uft.2447-4266.2018v4n2p298

La flamme d'une chandelle. Paris: PUF, 1961.

La formation de l'esprit scientifique. Paris: Vrin, 1972b.

Le nouvel esprit scientifique. Paris: PUF, 1978.

DELEUZE, G. Foucault. São Paulo: Brasiliense, 1988.

DESCARTES, R. Regras para a direção do espírito. Lisboa: Estampa, 1972.

DIDEROT, D. "Cabinet d'Histoire Naturelle", in Choix d'aricles de l'Encyclopédie. Antologie preparée et préfacée par Marie Leca-Tsiomis. Paris: Ed. Du CTHS, 2001 (tradução do autor).

Obras I e II. São Paulo: Perspectiva, 2001.

FOUCAULT, M. História da Sexualidade II: O uso dos prazeres. Rio de Janeiro: Graal, 1984.

Les mots et les choses. Paris: Gallimard, 1966.

Naissance de la clinique. Paris: PUF, 1972.

FOUCAULT, M. "Contracapa", in JACOB, F. La logique du vivant. Paris: Gallimard, 1970.

HEIDEGGER, M. Introdução à metafísica. Rio de Janeiro: Tempo Brasileiro, 1969.

JACOB, F. La logique du vivant. Paris: Gallimard, 1970.

KOYRÉ, A. Estudos de história do pensamento científico. Tradução de Márcio Ramalho. Rio de Janeiro: Forense Universitária, 1982.

MATURANA, H. A ontologia da realidade. Belo Horizonte: UFMG, 1997.

PRIGOGINE, I. \& STENGERS, I. A nova aliança. Brasília: UNB, 1984. 